\title{
ANALISIS PSIKOLOGI REMAJA DALAM ANTOLOGI KARYA SASTRA SUARA-SUARA BANGKU SEKOLAH
}

\section{ANALYZE OF TEENAGER PSYCHOLOGY IN LITTERATURE ANTHOLOGY SUARA-SUARA BANGKU SEKOLAH}

\author{
Adek Dwi Oktaviantina \\ Kantor Bahasa Banten \\ Jalan Bhayangkara 17 A, Cipocok Jaya, Serang, Banten, 42121 \\ Pos-el: dcsunardi@gmail.com
}

*) Naskah diterima: 4 November 2019; direvisi: 15 November 2019; disetujui: 5 Desember 2019

\begin{abstract}
Abstrak
Antologi Suara-Suara Bangku Sekolah adalah antologi hasil literasi sekolah melalui kegiatan Kantor Bahasa Banten bekerja sama dengan SMAN 5 Kota Cilegon. Cerpen dan puisi siswa SMAN 5 Kota Cilegon merupakan hasil karya literasi sastra yang memuat karya sesuai dengan psikologi remaja. Rumusan masalah penelitian adalah bagaimanakah analisis psikologi sastra dalam antologi karya sastra Suara-Suara Bangku Sekolah. Tujuan penelitian adalah mendeskripsikan psikologi remaja dalam Antologi karya sastra Suara-Suara Bangku Sekolah oleh SMAN 5 Cilegon. Metode yang digunakan adalah metode kualitatif. Teori yang digunakan adalah teori psikologi sastra. Hasil penelitian adalah puisi remaja dalam kumpulan puisi Suara-Suara Bangku Sekolah karya literasi SMAN 5 Kota Cilegon berisi tentang perkembangan psikologi remaja yang memiliki tema dan amanat berkaitan empati sosial, hubungan sosial, kasih sayang keluarga, refleksi diri, dan kepedulian sosial. Kelima tema tersebut menunjukkan bahwa siswa SMN 5 Kota Cilegon memiliki perkembangan psikologi remaja yang sesuai dengan perkembangan remaja seusia mereka yang berkembang dengan baik.
\end{abstract}

Kata kunci: puisi, psikologi sastra

\begin{abstract}
Anthology of School School Sounds by SMAN 5 Cilegon is the anthology of the results of school literacy through the Banten Language Office activities in collaboration with high schools. High school students' short stories and poems are literary works that contain works in accordance with adolescent psychology. The formulation of the research problem is how the analysis of literary psychology in the anthology of the works of the Suara Bangku Sekolah by SMAN 5 Cilegon. The purpose of this research is to describe adolescent psychology in the Anthology of the work of the Suara Bangku Sekolah by of SMAN 5 Cilegon. The method used is a qualitative method. The theory used is the theory of literary psychology. The results of the study are teenage poems in the collection of School Sounds by the students of SMAN 5 Cilegon literacy students, which contain the development of adolescent psychology that has themes and mandates relating to social empathy, social relationships, family love, self-reflection, and social care. The five themes show that students of SMAN 5 Cilegon have adolescent psychology development that is in accordance with the development of adolescents their age who are developing well.
\end{abstract}

Password: poetry, psychology of literature 


\section{PENDAHULUAN}

Karya sastra perlu diperkenalkan pada usia remaja. Remaja yang berkarya menghasilkan puisi, cerpen, novel, dan bentuk karya lainnya adalah remaja yang telah berkarya literasi di sekolah dan lingkungan sekitar. Literasi sejak dini memberikan jalan siswa untuk rajin membaca. Setelah itu, proses reproduksi bahasa memperkuat penguasaan literasi yaitu kegiatan menulis. Menurut Ayu Utami (2017:174), menulis merupakan media mengekspresikan diri. Menulis pun merupakan cara menyatakan pendapat atau perasaan tentang sebuah permasalahan. Menulis mampu untuk menyalurkan emosi pribadi dan ketegangan jiwa.

Salah satu fungsi menulis yaitu untuk menyalurkan emosi pribadi serta media mengekspresikan diri. Menulis merupakan salah satu hal yang dilakukan untuk mengatasi kegalauan serta media untuk mencurahkan isi hati bagi remaja. Menulis merupakan bagian perwujudan kreativitas siswa dalam menuangkan imajinasinya. Siswa dapat menyalurkan imajinasinya dalam puisi dan cerpen sehingga karya siswa menjadi sebuah karya literasi yang bermanfaat untuk pengembangan dirinya sebagai peningkatan daya saing sumber daya manusia.

Salah satu bentuk pengekspresian sastra oleh siswa yaitu dengan menulis puisi dan cerita fiksi. Puisi adalah karya estetis yang memanfaatkan sarana bahasa secara khas. Puisi juga luapan perasaan atau imajinasi penyair yang beroperasi pada persepsipersepsi penyair sehingga menggambarkan suasana emosi yang merupakan penggambaran dan pengekspresian gagasan perasaan, pandangan, dan sikap penyair. Dari unsur bahasa, puisi memiliki bahasa yang pekat dan padat. (Sayuti, 2010: 26). Unsur-unsur yang ada di dalam puisi memiliki nilai rasa yang diekspresikan oleh penyair dengan mengontemplasikan makna-makna.
Kesenangan terhadap sastra adalah kesenangan adigung yang menerbitkan rasa haru. Hiburan yang diberikan oleh sastra adalah hiburan spiritual (Adi, 2016:75). Oleh karena itu, karya sastra dalam hal ini cerita fiksi dan puisi merupakan media baik untuk mengekspresikan perkembangan mental dan kognitif siswa. Di dalam sebuah puisi dan ceria pendek, terdapat tema dan amanat yang di dalamnya terdapat pesan kuat untuk pembentukan karakter remaja.

Karakter adalah suatu kesadaran, kesadaran bersama, sebagai kesadaran berbangsa dan bertanah air bahwa segala sesuatu merupakan milik bersama. Hal yang paling menentukan adalah diri sendiri yang mengandung kesadaran pribadi yang memang sulit diubah apalagi orang lain (Ratna, 2014:281). Karakter tersebut tidak bisa muncul serta merta tetapi perlu pembiasaan hingga melekat di diri seseorang. Pembelajaran mengenai karakter perlu dimulai sejak dini dan diajarkan melalui semua mata pelajaran termasuk tentang sastra Indonesia.

Antologi karya sastra tersebut merupakan kumpulan karya puisi dan cerpen siswa binaan Kantor Bahasa Banten pada tahun 2016. Kegiatan tersebut dilaksanakan pada setiap hari Sabtu selama 3 bulan di SMAN 5 Cilegon. Kantor Bahasa Banten bekerja sama dengan sastrawan Lentera Internasional yang diketuai oleh M. Rois Rinaldi. Pada akhir kegiatan selama 3 bulan menghasilkan penampilan teater SMAN 5 Cilegon yang ditampilkan pada Jambore Sastra di Jawa Tengah tahun 2016. Antologi tersebut adalah karya siswa SMAN 5 Kota Cilegon yang dibukukan dan diterbitkan oleh Kantor Bahasa Banten dengan judul Suara-Suara Bangku Sekolah. Rumusan masalah penelitian adalah bagaimanakah analisis psikologi sastra dalam antologi karya sastra SuaraSuara Bangku Sekolah. Tujuan penelitian adalah mendeskripsikan psikologi remaja 
dalam Antologi karya sastra Suara-Suara Bangku Sekolah oleh SMAN 5 Cilegon

\section{TEORI}

Penelitian sebelumnya mengenai analisis psikologi sastra adalah penelitian berjudul "Analisis Psikologi Sastra dan Nilai Pendidikan dalam Novel "Entrok" karya Okky Madasari serta Relevansinya sebagai Materi Pembelajaran Sastra di Sekolah Menengah Atas". Artikel tersebut ditulis oleh Rika Endri Astuti, Yanto Mujiyanto, dan Muhammad Rohmadi. Artikel tersebut diterbitkan di jurnal Basastra Volume 4 Nomor 2, Oktober tahun 2016. Hasil penelitiannya, yaitu struktur yang membangun Novel Entrok bertema feminisme. Tokoh utama ada dua, yaitu Marni dan Rahayu. Latar tempat novel tersebut meliputi Magetan, Ngawi, Jogjakarta, dan Semarang. Sudut pandangnya menggunakan teknik akuan. Amanat novel adalah ketidakadilan yang terjadi pada Orde Baru. Selain itu, penelitian tersebut mendeskripsikan analisis kejiwaan tokoh utama dalam Novel Entrok dengan teori psikoanalisis id, ego, dan superego Sigmund Freud yang dipengaruhi oleh faktor luar dan dalam. Nilai-nilai yang terdapat dalam novel tersebut adalah religius. Hal itu tampak pada sikap tokoh Rahayu yang menunjukkan sikap taat agama. Nilai lainnya adalah nilai sosial yang ditunjukkan melalui sikap patrialisme Marni. Nilai moral dicontohkan dengan sikap tokoh Rahayu yang menolong tokoh Ndari. Nilai sejarah tampak pada latar yang mengingat kembali masa orde baru. Keempat hal ini memiliki relevansi sehingga novel "Entrok" layak menjadi bahan pembelajaran sasra sesuai dengan KD 15.1 dan 15. 2 di SMA Muhammadiyah 1 Karanganyar (Astuti,dkk., 2016:175-176).

Penelitian lainnya adalah penelitian berjudul "Analisis Tokoh Utama dengan Teori Psikoanalisa Sigmeund Freud pada
Cerpen Hanakarya Akutagawa Ryounosuke" yang ditulis oleh Siti Rokhana dari Jurusan Bahasa Jepang Universitas Negeri Semarang pada skripsinya tahun 2009. Penelitian Rokhana mendeskripsikan aspek psikologis tokoh utama dalam $i d$, ego, dan superego serta mendeskripsikan faktorfaktor yang mempengaruhi kejiwaan tokoh utama. Hasil penelitian menunjukkan bahwa ego Naigu dapat menyanggupi id dari Naigu yang besar. Namun, superego belum bekerja sempurna untuk mengendalikan id dari Naigu. Secara garis besar, gejolak psikologis dari tokoh Naigu dibagi menjadi 2,yaitu (1) faktor yang mempengaruhi Naigu memendekkan hidungnya, antara lain faktor biologis, motif pemenuhan diri, faktor sosial, faktor psikososial, motif harga diri dan kebutuhan mencari identitas diri, (2) faktor yang mempengaruhi Naigu ingin hidung panjangnya kembali seperti semula, antara lain, faktor psikososial dan faktor emosi. (Rokhana, 2009: vii).

Penelitian ini membahas psikologi sastra melalui tema dan amanat dalam cerita melalui teori psikologi perkembangan remaja yang terdapat dalam kumpulan puisi 'SuaraSuara Bangku Sekolah" oleh SMAN 5 Cilegon. Secara psikologis perkembangan remaja dapat diamati melalui teori tahaptahap perkembangan kognitif yang dicetuskan oleh Piaget. Pada anak usia 13 dan adolesen tersebut, anak mengalami pemfungsian tahap operasional formal (Piaget), yaitu kemampuan untuk memprediksi, menginferensi, berhipotesis tanpa referensi. Anak juga mengalami pengalaman tahap identitas versus kebingungan dan beralih ke tahap otonomi moral. Pada tahap berikutnya, anak menunjukkan kebebasannya dari keluarga sebagai langkah menuju awal kedewasaan. Tahap selanjutnya, anak mengidentifikasikan diri dengan dewasa yang dikagumi. Selanjutnya, anak menunjukkan ketertarikannya pada isu-isu filosofis, etis, dan religius. 
Pada tahap akhir, anak mencari sesuatu yang idealistis (Nurgiyantoro, 2016:63).

Menurut Tarigan (2011:52-53), perkembangan psikologi anak sangat penting untuk diperhatikan dalam memahami diri mereka. Sastra yang dikembangkan melalui teks-teks mampu menunjang perkembangan pribadi yang positif melalui berbagai pengalaman. Pada penelitian Maslow dalam Tarigan (2011:53), disarankan dan ditegaskan bahwa seorang insan tumbuh dan berkembang melalui suatu hierarki kebutuhan dimulai kebutuhan paling dasar, yaitu kebutuhan fisiologis hingga kebutuhan yang lebih tinggi, yaitu perkembangan remaja secara secara insani dan spiritual.

\section{METODE}

Metode penelitian ini adalah metode penelitian kualitatif. Metode penelitian kualitatif adalah metode yang biasanya dilakukan dalam studi sastra dan juga menjadi penting dalam penelitian ilmu-ilmu sosial (Adi, 2016: 239). Metode pengumpulan data yang digunakan menggunakan teknik catat dan studi pustaka. Studi pustaka untuk menemukan segala sumber yang berkaitan dengan objek penelitian (Faruk, 2015:56). Ciri utama paparan deskriptif adalah unitisasi, artinya analisis dikerjakan berdasarkan tiaptiap topik, tema, feature, konsep, atau unsur (Siswantoro, 2010:81).

Langkah-langkah untuk melakukan analisis data puisi, yaitu yang pertama memilih pendekatan yang tepat untuk menganalisis puisi, setelah itu memilih puisi atau cerpen yang akan dianalisis. Langkah berikutnya adalah menyusun hipotesis awal setelah melakukan pembacaan. Langkah berikutnya, yaitu memarafrasekan puisi. Setelah puisi diparafrasekan baru dianalisis sesuai dengan tema dan topik yang akan diangkat. Langkah-langkah yang dilakukan untuk menganalisis cerpen adalah mengumpulkan cerpen yang akan dianalisis dan menentukan tema dan amanat masing-masing cerpen. Langkah terakhir adalah menganalisis data dalam tema dan amanat yang menggambarkan situasi sesuai dengan pendekatan yang telah ditentukan.

\section{PEMBAHASAN}

\section{Tema dan Amanat Puisi Suara-Suara Bangku Sekolah}

Tema adalah sikap pengarang terhadap subjek cerita dan ditemukan dalam suatu cerita (Sayuti, 2017: 202). Tema memuat apa yang ingin disampaikan oleh penulis kepada pembaca secara eksplisit dan implisit. Penentuan tema bisa ditentukan dengan dua kriteria. Pertama, penafsiran yang mempertimbangkan detail cerita untuk menemukan pengedepanan oleh penulis, kedua, penentuan tema tidak bertentangan dengan detail cerita, dan ketiga, penafsiran tema hendaknya tidak dinyatakan bukti yang tidak dinyatakan dengan baik secara langsung dan tidak langsung dalam karya fiksi (Sayuti, 2017:206).

Tema cerita hendaknya bermanfaat untuk pertumbuhan orang muda dan didasarkan pada prinsip keadilan dan kejujuran. Moral yang logis, akhlak yang sehat, dan prinsip-prinsip etis hendaklah berlaku (Tarigan, 2011:116). Hakikat amanat cerita adalah sesuatu hal yang baik yang ingin disampaikan kepada pembaca. (Nurgiyantoro, 2016:265). Oleh karena itu, tema berhubungan secara tidak langsung dengan amanat cerita untuk mendukung perkembangan psikologi remaja. Berikut ini tema dan amant puisi dalam antologi karya sastra Suara-Suara Bangku Sekolah. 
Tabel 3.1. Tema dan Amanat Puisi dalam Antologi

Karya Sastra Suara-Suara Bangku Sekolah

\begin{tabular}{|c|c|c|c|c|}
\hline No & $\begin{array}{l}\text { Nama } \\
\text { Penulis }\end{array}$ & Judul Puisi & Tema & Amanat/Pesan/Moral cerita \\
\hline \multirow[t]{2}{*}{1} & \multirow[t]{2}{*}{$\begin{array}{l}\text { Valennisa } \\
\text { Qunifah }\end{array}$} & $\begin{array}{l}\text {-Lelaki Penyusun } \\
\text { Bata-Batu }\end{array}$ & Empati sosial & $\begin{array}{l}\text { Pekerjaan apa saja baik asal dilakukan } \\
\text { dengan rajin dan kerja keras }\end{array}$ \\
\hline & & Langit dan Bumi & Lingkungan & $\begin{array}{l}\text { Alam diciptakan sang Maha Pencipta } \\
\text { untuk dijaga }\end{array}$ \\
\hline \multirow[t]{2}{*}{2} & \multirow{2}{*}{$\begin{array}{l}\text { Fidella D. } \\
\text { Alifia }\end{array}$} & -Impian & Tujuan hidup & Raihlah impian selagi kita mampu \\
\hline & & -Pada Musim Itu & $\begin{array}{l}\text { Kepedulian } \\
\text { sosial }\end{array}$ & Tepatilah janji \\
\hline \multirow[t]{2}{*}{3} & \multirow{2}{*}{$\begin{array}{l}\text { Diana Fitri } \\
\text { Astuti }\end{array}$} & Entah & Refleksi diri & Manfaatkan pengalaman hidup \\
\hline & & Senja & Refleksi diri & Jangan ada penyesalan dalam hidup \\
\hline \multirow[t]{2}{*}{4} & \multirow[t]{2}{*}{$\begin{array}{l}\text { Vivin } \\
\text { Novalia }\end{array}$} & Hallowen Party & $\begin{array}{l}\text { Hubungan } \\
\text { sosial }\end{array}$ & $\begin{array}{l}\text { Janganlah terjebak pada hubungan } \\
\text { yang merugikan }\end{array}$ \\
\hline & & Guru & Empati Sosial & Hormati guru \\
\hline \multirow[t]{4}{*}{5} & \multirow[t]{4}{*}{$\begin{array}{l}\text { Putri } \\
\text { Noviyanah }\end{array}$} & Mutiaraku & $\begin{array}{l}\text { Kasih sayang } \\
\text { pada keluarga }\end{array}$ & Cintai ibu \\
\hline & & $\begin{array}{l}\text { Pada Waktu yang } \\
\text { Akan Datang }\end{array}$ & Tujuan hidup & $\begin{array}{l}\text { Sebaiknya tetap bersetia pada } \\
\text { hubungan }\end{array}$ \\
\hline & & Koruptor & Kritik sosial & Janganlah mengorupsi uang negara \\
\hline & & Tugasku & $\begin{array}{l}\text { Kehidupan } \\
\text { sehari hari }\end{array}$ & Kerjakanlah tugas dengan rajin \\
\hline \multirow[t]{2}{*}{6} & \multirow[t]{2}{*}{$\begin{array}{l}\text { Vivi } \\
\text { Octavia }\end{array}$} & Unicorn & $\begin{array}{l}\text { Hubungan } \\
\text { sosial }\end{array}$ & Jangan berputus asa dalam hidup \\
\hline & & Tangisan Malam & Refleksi diri & $\begin{array}{l}\text { Minta ampunlah atas dosa kepada } \\
\text { Tuhan }\end{array}$ \\
\hline \multirow[t]{2}{*}{7} & \multirow[t]{2}{*}{$\begin{array}{l}\text { Monika } \\
\text { Wardini }\end{array}$} & $\begin{array}{l}\text { Sang Pembangun } \\
\text { Istana }\end{array}$ & Keluarga & Sayangi keluarga \\
\hline & & Andai & Empati Sosial & $\begin{array}{l}\text { Mumpung masih muda, belajar } \\
\text { dengan tekun }\end{array}$ \\
\hline \multirow[t]{2}{*}{8} & \multirow[t]{2}{*}{ Maelani } & $\begin{array}{l}\text { Kemelut } \\
\text { Perempuan }\end{array}$ & Refleksi diri & Jadilah perempuan yang kuat \\
\hline & & Teman Hidup & $\begin{array}{l}\text { Hubungan } \\
\text { sosial }\end{array}$ & Sayangi sahabat \\
\hline \multirow[t]{2}{*}{9} & \multirow[t]{2}{*}{$\begin{array}{l}\text { Reni } \\
\text { Firayanti }\end{array}$} & Rindu & $\begin{array}{l}\text { Sayang } \\
\text { keluarga }\end{array}$ & Sayangi ayahmu \\
\hline & & Saat Fajar & Refleksi diri & $\begin{array}{l}\text { Manfaatkan waktu mudamu untuk } \\
\text { meraih cita }\end{array}$ \\
\hline \multirow[t]{2}{*}{10} & \multirow[t]{2}{*}{ Elma Sofia } & Kata Pensil & Empati sosial & $\begin{array}{l}\text { Tersenyumlah meski masalah } \\
\text { mendera }\end{array}$ \\
\hline & & Suara Rakyat & Kritik sosial & Dengarkan suara rakyat \\
\hline
\end{tabular}




\begin{tabular}{|c|c|c|c|c|}
\hline No & $\begin{array}{l}\text { Nama } \\
\text { Penulis }\end{array}$ & Judul Puisi & Tema & Amanat/Pesan/Moral cerita \\
\hline \multirow[t]{2}{*}{11} & \multirow[t]{2}{*}{ A.Husna } & Ruang Kosong & Refleksi diri & Kematian bisa datang kapan pun \\
\hline & & Anak Koin & Empati sosial & $\begin{array}{l}\text { Pekerjaan apa pun lakukan dengan } \\
\text { baik }\end{array}$ \\
\hline \multirow[t]{2}{*}{12} & \multirow[t]{2}{*}{$\begin{array}{l}\text { Windi } \\
\text { Maylawati }\end{array}$} & Ibu & $\begin{array}{l}\text { Kasih sayang } \\
\text { keluarga }\end{array}$ & Cintai Ibu \\
\hline & & Kamu & $\begin{array}{l}\text { Hubungan } \\
\text { sosial }\end{array}$ & Sayangi sahabatmu \\
\hline \multirow[t]{2}{*}{13} & \multirow{2}{*}{$\begin{array}{l}\text { Ana } \\
\text { Prasetya }\end{array}$} & Waktu & Tujuan hidup & Raihlah citamu \\
\hline & & Hidup Ini & Refleksi diri & $\begin{array}{l}\text { Semangatlah dalam menjalani } \\
\text { kehidupan }\end{array}$ \\
\hline \multirow[t]{2}{*}{14} & \multirow[t]{2}{*}{$\begin{array}{l}\text { Firda } \\
\text { Amalia }\end{array}$} & Ibuku & $\begin{array}{l}\text { Kasih sayang } \\
\text { keluarga }\end{array}$ & Cintai ibu \\
\hline & & Selamat Pagi & Refleksi diri & $\begin{array}{l}\text { Pergunakan dengan baik masa } \\
\text { mudamu }\end{array}$ \\
\hline \multirow[t]{2}{*}{15} & \multirow[t]{2}{*}{$\begin{array}{l}\text { Andi } \\
\text { Darmawan }\end{array}$} & Seolah Aku & $\begin{array}{l}\text { Hubungan } \\
\text { sosial }\end{array}$ & $\begin{array}{l}\text { Perbaikilah hubungan sosial dengan } \\
\text { teman }\end{array}$ \\
\hline & & Keraguan & Refleksi diri & Dekatkan diri dengan tuhan \\
\hline 16 & $\begin{array}{l}\text { Kristia } \\
\text { Pujiawati }\end{array}$ & Muslimah & Refleksi diri & $\begin{array}{l}\text { Bersikaplah lebih baik untuk diri } \\
\text { sendiri }\end{array}$ \\
\hline
\end{tabular}

Tujuh belas siswa menulis 35 puisi dengan berbagai tema dan amanat. Menurut pengelompokan tema, tema empati sosial sebanyak lima puisi $(14,28 \%)$, hubungan sosial keluarga sebanyak tujuh puisi $(20 \%)$, refleksi diri sebanyak sepuluh puisi $(28,5 \%)$, tema hubungan sosial masyarakat sebanyak empat puisi $(11,4 \%)$, tema tujuan hidup sebanyak tiga puisi $(8,5 \%)$, dan tema lingkungan hanya satu puisi (2,86\%).

Pada tema dan amanat puisi yang digubah oleh siswa SMAN 5 Kota Cilegon tersebut terdapat tema keseharian remaja tentang refleksi diri, hubungan sosial, keluarga, empati sosial, kepedulian lingkungan, dan tujuan hidup. Pada usia SMA, siswa tidak membatasi pada pengetahuan tentang individu saja, tetapi siswa mulai menum- buhkan perhatian terhadap sekitarnya yaitu dengan membuat puisi tentang simpati dan hubungan sosial.

Menurut Kohlberg dalam Tarigan (2011:55), perkembangan moral anak-anak pada tahap lima dan enam. Pada tahap lima, anak mengetahui kriteria tingkah laku yang benar kini dipahami atau didasarkan dalam kaitannya dengan aturan umum yang standar dan yang disetujui oleh atau telah menjadi konvensi masyarakat. Tahap enam, yaitu keputusan-keputusan individual kini didasarkan pada kata hati, hati nurani, dan etika yang berlaku secara konsisten, dan universal (Tarigan, 2011: 55). Berikut ini tema dan amanat cerita pendek dalam Antologi karya Sastra Suara-Suara Bangku Sekolah. 
Tabel 3.2. Tema dan Amanat Cerita Pendek dalam Antologi Karya Sastra Suara-Suara Bangku Sekolah

\begin{tabular}{|c|c|c|c|c|}
\hline No & Nama Penulis & Judul Cerpen & Tema & Amanat \\
\hline 1. & Ami Amalia & Metamorfosis & Keluarga & $\begin{array}{l}\text { Sebaiknya orang tua menyisihkan } \\
\text { waktu untuk berkomunikasi } \\
\text { dengan anak }\end{array}$ \\
\hline 2. & Firda Amailia & Hijrah Akhwat & $\begin{array}{l}\text { Religi, } \\
\text { persahabatan }\end{array}$ & $\begin{array}{l}\text { Laksanakan perintah Allah agar } \\
\text { menjadi pribadi lebih baik }\end{array}$ \\
\hline 3. & Kristia Pujiawati & Rani & $\begin{array}{l}\text { Kepedulian } \\
\text { sosial }\end{array}$ & $\begin{array}{l}\text { Bekerja keras sejak usia muda dan } \\
\text { pantang menyerah }\end{array}$ \\
\hline 4. & Valennisa & $\begin{array}{l}\text { Ritus Yem Pii } \\
\text { Yek }\end{array}$ & $\begin{array}{l}\text { Kasih sayang } \\
\text { keluarga }\end{array}$ & $\begin{array}{l}\text { Jangan membantah dan melawan } \\
\text { orang tua }\end{array}$ \\
\hline 5. & Vivin Novalia & $\begin{array}{l}\text { Teka Teki } \\
\text { Dompet Audi }\end{array}$ & $\begin{array}{l}\text { Kepedulian } \\
\text { sosial }\end{array}$ & $\begin{array}{l}\text { Bersikaplah ksatria untuk } \\
\text { mengakui kesalahan }\end{array}$ \\
\hline 6. & Elma Sofia & $\begin{array}{l}\text { Daftar Hadir di } \\
\text { Waktu Duha }\end{array}$ & Persahabatan & $\begin{array}{l}\text { Saling mengingatkan dalam } \\
\text { kebaikan }\end{array}$ \\
\hline 7. & Fidela Devina & $\begin{array}{l}\text { Penghubung } \\
\text { Masa Depan }\end{array}$ & $\begin{array}{l}\text { Kepedulian } \\
\text { lingkungan }\end{array}$ & Tolong menolong dalam kebaikan \\
\hline 8. & Putri Noviyanah & Kenangan & Persahabatan & $\begin{array}{l}\text { Ikhlas terhadap kematian } \\
\text { seseorang }\end{array}$ \\
\hline 9 & Vivi Oktavia & $\begin{array}{l}\text { Denger Dong, } \\
\text { Gis! }\end{array}$ & Persahabatan & Janganlah bersikap egois \\
\hline 10 & Windi Maylawati & Kacamata Gaib & $\begin{array}{l}\text { Kepedulian } \\
\text { Sosial }\end{array}$ & Sayangilah sesama manusia \\
\hline 11 & Andi Darmawan & Love Rain & persahabatan & Sayangi sahabat \\
\hline 12 & M. Nasir & $\begin{array}{l}\text { Tidur Tak } \\
\text { Berselimut }\end{array}$ & $\begin{array}{l}\text { Kasih sayang } \\
\text { keluarga }\end{array}$ & Cintai keluargamu \\
\hline
\end{tabular}

Menurut pengelompokan tema, tema hubungan sosial masyarakat terdapat tiga cerpen $(25 \%)$, tema hubungan sosial persahabatan terdapat lima cerpen (41\%), tema kepedulian sosial terdapat tiga cerpen (25\%) dan tema kepedulian lingkungan terdapat satu cerpen $(8 \%)$.

\section{Puisi dan Cerpen Remaja Bertema Empati Sosial}

Pada antologi puisi Suara-Suara Bangku Sekolah, terdapat lima puisi bertema empati sosial. Empat puisi tersebut adalah puisi "Lelaki Penyusun Bata-Batu" karya Valennisa Qunifah, "Guru" karya Vivin Novalia, "Andai" karya Monika Wardini, dan "Anak Koin” karya A. Husna. Puisi “Lelaki Penyu- 
sun Bata-Batu" bertutur tentang aktivitas lelaki pembuat batu bata dari tanah liat. Puisi "Guru" menceritakan profesi guru yang membimbing si penulis puisi. Puisi "Andai" berkisah tentang pekerjaan pengemis di pinggir jalan sebagai sebuah pekerjaan yang ingin dihindari, dan "Anak Koin" bercerita tentang kehidupan anak pencari koin di pelabuhan.

Empati adalah sebuah keadaan emosi, tetapi memiliki komponen kognitif-kemampuan untuk melihat keadaan psikologis dalam diri orang lain, atau apa yang disebut sebagai pengambilan perspektif. Perasaan positif seperti empati memberikan kontribusi terhadap perkembangan moral anak. Merasakan empati berarti beraksi terhadap perasaan orang lain dengan respons emosional yang mirip dengan perasaan orang lain (Damon dalam Santrock, 2007:129).

Puisi bertema empati sosial dalam kumpulan puisi dan cerpen $S S B B$ sejumlah lima puisi atau $14,28 \%$ dari total keseluruhan. Empati sosial tercipta saat hati nurani remaja tergerak melihat kesenjangan yang ada di depan matanya. Puisi tersebut merupakan media remaja untuk mengekspresikan dan menyampaikan empati dalam bentuk katakata. Remaja berempati saat melihat seseorang lelaki yang menyusun batu-batu. Puisi gubahan Valenisa Qunifah menceritakan kehidupan seorang kuli yang membuatnya berempati dengan kehidupan kuli tersebut.

Vivin Novalia berempati pada profesi guru dan Monika Wardani berempati terhadap sebuah kondisi seseorang yang tidak memungkinkan untuk berpendidikan tinggi dan menjadi pengemis di hari tuanya. A. Husna tumbuh rasa empatinya saat melihat keseharian anak kecil yang harus terjun ke laut untuk mencari koin sebagai penghidupan sehari-harinya. Puisi-puisi di atas menunjukkan sikap empati sosial yang tumbuh di kalangan remaja sebagai tanda tumbuhnya hati nurani dan hal ini dekspresikan melalui puisi.

\section{Puisi dan Cerpen Remaja Bertema Hubungan dan Kepedulian Sosial}

Remaja harus mengenal hubungan sosial baik antar sesama rekan sebaya maupun dengan lintas usia. Remaja dengan hubungan sosial yang baik akan terhindar dari perbuatan antisosial. Pertemanan memiliki enam fungsi (Gottman \& Parker, 1987 dalam Santrock, 2007:220). Pertemanan memiliki fungsi sebagai persahabatan. Siswa menemukan rekan yang familiar, yaitu seseorang yang mau menghabiskan waktu bersama mereka dan bergabung dalam aktivitas kolaboratif. Fungsi pertemanan berikutnya adalah sebagai stimulasi. Dengan berteman, anak-anak mendapatkan informasi yang menarik, memberikan kesenangan, dan hiburan. Pertemanan berfungsi untuk memberikan dukungan fisik karena di dalamnya terdapat sumber daya dan bantuan. Dalam pertemanan pun, terdapat dukungan ego, yaitu terdapat harapan akan dukungan, semangat, dan umpan balik yang membantu anak-anak memelihara kesan diri mereka sendiri sebagai individu yang kompeten, menarik, dan pantas ditemani. Pertemanan juga menyediakan informasi tentang posisi anak-anak terhadap orang lain dan apakah anak-anak tersebut berlaku baik. Yang terakhir, dalam pertemanan, anak-anak mengalami hubungan yang hangat, dekat, dan saling memercaya dengan individu yang lain, yaitu hubungan yang melibatkan keterbukaan diri (Santrock, 2007:220-221).

Hubungan sosial melingkupi hubungan siswa dengan teman sebaya, keluarga, dan lintas usia. Puisi yang bertema hubungan sosial pada kumpulan puisi dan cerpen SSBS berjumlah tujuh puisi untuk hubungan sosial keluarga (20\%) dan lima puisi hubungan sosial masyarakat $(11,4 \%)$. Cerita pendek tentang hubungan sosial persahabatan terdapat lima cerpen (41\%) dan hubungan sosial masyarakat sejumlah tiga cerpen (25\%). 
Cerpen karya Putri Noviyanah bertema persahabatan berjudul "Kenangan". Cerpen ini memiliki tema menarik yaitu seorang remaja yang merasa kehilangan sahabatnya yang telah terpisahkan oleh kematian. Salah satu cara untuk tetap mengingat, yaitu dengan menuliskan kenangan tentang sahabat yang telah meninggal. Hal ini merupakan sebuah dukungan ego terhadap sahabat karena dalam hal pertemanan terdapat rasa saling percaya dan bersikap hangat terhadap teman sebaya. Sikap keterbukaan dan percaya merupakan sikap yang harus ditumbuhkan ketika usia remaja karena pada masa dewasa nantinya, sikap kepercayaan merupakan modal untuk melangkah ke depan.

Cerita pendek pada antologi karya sastra SSBS bertema kepedulian sosial terdapat tiga cerpen $(25 \%)$ dari total keseluruhan. Kepedulian sosial merupakan bagian dari pendidikan karakter yang berkembang pada diri remaja. Pada usia ini, remaja memulai untuk pengambilan perspektif, yaitu remaja menyadari pengambilan perspektif yang berlangsung secara bersama tidak selalu menghasilkan perasaan memahami yang lengkap. Konvensi sosial dipandang perlu karena dimengerti oleh seluruh anggota kelompok terlepas dari posisi, pengalaman, atau perannya (Santrock, 2007:59).

Kepedulian sosial tumbuh saat remaja mampu mengambil perspektif orang lain dan memahami perasaan dan pikiran mereka. Proses inilah yang menimbulkan perasaan peduli pada orang lain dan menghadirkan respons berupa ekspresi pada puisi agar orang lain pun merasakan kepedulian yang mereka rasakan.

\section{Puisi dan Cerpen Remaja Bertema Refleksi Diri, Kepedulian Lingkungan, dan Tujuan Hidup}

Puisi pada antologi karya sastra SSBS bertema refleksi diri sebanyak sepuluh puisi
(28,5 \%). Pada masa remaja, remaja mengalami self-conscioussness (kesadaran diri) untuk kali pertama (Santrock, 2007:57). Remaja belajar untuk mengenal egonya sendiri dan disibukkan dengan kegiatan pemahaman diri. Refleksi diri merupakan dari perkembangan kognitif dan moral pada usia remaja.

Remaja merefleksikan diri terhadap masa mudanya untuk dimanfaatkan dengan baik agar tidak menyesal di hari tua. Remaja juga merefleksikan dirinya agar mengingat kematian dan mendekatkan diri kepada Tuhan. Remaja juga merefleksikan dirinya untuk bersikap lebih baik untuk dirinya sendiri. Refleksi diri merupakan sebuh jalan untuk sebuah perbaikan baik dalam moral maupun spriritual. Diana Fitri Astuti, Vivi Octavia, Maelani, Reni Firayanti, dan A. Husna berkisah tentang refleksi diri yang dilakukannya dan menuangkan pikiran serta harapannya dalam puisi yang mereka buat.

Puisi pada antologi karya sastra SSBS bertema kepedulian terhadap lingkungan hanya satu puisi $(2,86 \%)$. Cerpen bertema kepedulian lingkungan terdapat satu cerpen yaitu 8\% Lingkungan merupakan wilayah kontak bagi remaja dan hal tersebut tentu menimbulkan minat terhadap sesuatu yang ada di sekitar remaja. Saat remaja mendapati sebuah kondisi yang terasa memilukan dan membutuhkan perhatian secara menyeluruh maka remaja akan mengekspresikan dalam bentuk puisi apa yang ada di sekitarnya.

Puisi pada antologi karya sastra SSBS bertema tujuan hidup sebanyak tiga puisi $(8,5 \%)$. Siswa pada usia remaja sudah mengenal self-esteem. Self-esteem yaitu penilaian seseorang untuk dirinya. Self-esteem inilah yang menghadirkan persepsi keberhargaan seseorang dan menimbulkan tujuan hidup sehingga tercipta individu dengan pencapaian tertentu. 


\section{SIMPULAN DAN SARAN}

Antologi karya sastra berjudul SuaraSuara Bangku Sekolah merupakan antologi karya sastra siswa hasil binaan literasi Kantor Bahasa Banten bekerja sama dengan komunitas sastra Cilegon dan SMAN 5 Kota Cilegon. Dua belas siswa menulis dua belas cerpen. Menurut pengelompokan tema, tema hubungan sosial masyarakat terdapat tiga cerpen $(25 \%)$, tema hubungan sosial persahabatan terdapat lima cerpen $(41 \%)$, tema kepedulian sosial terdapat tiga cerpen (25\%), dan tema kepedulian lingkungan terdapat satu cerpen $(8 \%)$. Tujuh belas siswa menulis 35 puisi dengan berbagai tema dan amanat. Menurut pengelompokan tema, tema empati sosial sebanyak lima puisi $(14,28 \%)$, hubungan sosial keluarga sebanyak tujuh puisi (20\%) , refleksi diri sebanyak sepuluh puisi $(28,5 \%)$, tema hubungan sosial masyarakat sebanyak empat puisi $(11,4 \%)$, tema tujuan hidup sebanyak tiga puisi $(8,5 \%)$, dan tema lingkungan hanya satu puisi $(2,86 \%)$.

Puisi dan cerpen yang bertema hubungan dan kepedulian sosial merupakan salah satu bentuk perkembangan psikologi remaja yaitu tentang pertemanan yang mulai dibentuk dan diekspresikan menjadi puisi oleh remaja SMAN 5 Cilegon. Puisi dan cerpen bertema refleksi diri, kepedulian diri, dan tujuan hidup merupakan sebuah gambaran tentang perkembangan kognitif dan moral pada usia remaja. Kemampuan literasi menulis sama pentingnya dengan literasi membaca. Sejalan dengan itu, menjadi penting pula untuk mengapresiasi karya siswa SMAN 5 Cilegon. Puisi siswa tersebut sarat dengan pesan yaitu perlunya kerja keras, sifat rajin, keimanan, cita-cita, sikap menepati janji, belajar dari pengalaman masa lalu, dan menyayangi keluarga. Tulisan ini diharapkan memberikan inspirasi kepada siswa di seluruh Indonesia agar terus menulis dan berkarya.

\section{DAFTAR PUSTAKA}

Adi, Ida Rochani. 2016. Fiksi Populer: Teori dan Metode Kajian. Yogyakarta: Pustaka Pelajar.

Astuti. 2016. Analisis Psikologi Sastra dan Nilai Pendidikan dalam Novel Entrok karya Okky Madasari serta Relevansinya sebagai Materi Pembelajaran Sastra di Sekolah Menengah Atas. Basastra, Volume 4, Nomor 2 bulan Oktober.

Faruk, Prof. 2015. Metode Penelitian Sastra (Sebuah Penjelajahan Awal). Yogyakarta: Pustaka Pelajar.

Nurgiyantoro, Burhan. 2016. Sastra Anak:

Pengantar Pemahaman Dunia Anak. Yogyakarta: Gajah Mada University Press.

Ratna, Nyoman Kutha. 2014. Peranan Karya Sastra, Seni, dan Budaya dalam Pendidikan Karakter. Yogyakarta: Pustaka Pelajar.

Rokhana, Siti. 2009. Analisis Tokoh Utama dengan Teori Psikoanalisa Sigmeund Freud pada Cerpen Hanakarya Akutagawa Ryounosuke. Universitas Negeri Semarang: Skripsi tidak diterbitkan.

Santrock, John. W. 2007. Perkembangan Anak (Edisi Kesebelas Jilid 2). Jakarta: Penerbit Erlangga.

Sayuti, Suminto. 2010. Berkenalan dengan Puisi. Yogyakarta: Penerbit Gama Media.

- - - - - - - . 2017. Berkenalan

dengan Prosa Fiksi. Yogyakarta: Cantrik Pustaka

Siswantoro. 2010. Metode Penelitian Sastra (Analisis Struktur Puisi). Yogyakarta: Pustaka Pelajar.

Tarigan, Henry Guntur. 2011. Dasar-Dasar Psikosastra. Bandung: Penerbit Angkasa. Utami, Ayu. 2017. Menulis dan Berpikir Kreatif Cara Spiritualisme Kritis Jilid 1. Jakarta: Kepustakaan Populer Gramedia. 